\title{
A llustração para a infância em Portugal nas duas primeiras décadas do século $\mathrm{XX}$
}

\author{
The Illustration for children in Portugal in the first two decades of the \\ 20th century
}

RAMOS, Carla Maria

Universidade Lusófona do Porto - ULP I carla.cadete@ulp.pt

\begin{abstract}
Resumo
Em Portugal, durante a I República (1910-1926), os políticos consideravam essencial a formação escolar das gerações mais novas, uma vez que seriam estas a dar continuidade ao espírito revolucionário. Nesta época surgiram novos escritores, jornais e coleções infantis e, ainda que a maioria dos livros fosse de caráter educativo, verifica-se um novo espírito na escrita para crianças. Era necessário substituir o dever de obediência pelo sentimento cívico e pela ideia de responsabilidade de cada cidadão no progresso do país. Daí a introdução de novos temas nos livros para crianças como a História e/ou a Geografia do país, de que são testemunhos as obras dos grandes autores da época como Ana de Castro Osório, Virgínia de Castro e Almeida, Aquilino Ribeiro, António Sérgio, Fernanda de Castro e Jaime Cortesão. $\mathrm{Na}$ ilustração destaque para alguns dos mais exímios artistas portugueses da época, como as irmãs Mamia Roque Gameiro e Raquel Roque Gameiro, Alonso, Leal da Câmara e Milly Possoz, Sarah Afonso, entre outros. A preocupação com a alfabetização, a ampliação da rede escolar e a criação de bibliotecas, fez com que, a pouco e pouco, a leitura passasse a tomar o seu devido lugar.
\end{abstract}

Palavras-chave: ilustração para a infância. Ilustração para a infância em Portugal. llustração para a infância no início do século XX. O incentivo à leitura como política pública durante a I República portuguesa.

\section{Abstract}

In Portugal, during the First Republic (1910-1926), politicians considered the education of the younger generation to be of major importance, since they would continue to support the revolutionary spirit. At that time, new writers, newspapers and children's book collections appeared and, although the majority of them were for educational purposes, a new style in the writing for children was established. It was necessary to replace the duty of obedience with civic feeling and with the idea of responsibility of each citizen in the progress of the country. Hence the introduction of new themes in children's books such as the History and / or Geography of the country, which includes the works of great authors of the time, such as Ana de Castro Osório, Virgínia de Castro e Almeida, Aquilino Ribeiro, António Sérgio, Fernanda de Castro and Jaime Cortesão. In the illustration, we highlight some of the most exquisite Portuguese artists of the time, such as the sisters Mamia Roque Gameiro and Raquel Roque Gameiro, Alonso, Leal da Câmara and Milly Possoz, Sarah Afonso, among others. The concern with literacy, the expansion of the school network, and the creation of libraries led, little by little, to an appreciation for reading.

Keywords: Illustration for children. Illustration for children in Portugal. Portuguese illustration. Illustration for children in the beginning of the 20th century. Motivation to reading as public policy during the First Portuguese Republic. 


\title{
1 AS DUAS PRIMEIRAS DÉCADAS DO SÉCULO XX - ENQUADRAMENTO HISTÓRICO
}

O clima de entusiamo resultado da grande confiança que os avanços da técnica e da ciência proporcionavam desde o final do século XIX, marcaram o início do novo século que tomou o nome de Belle Époque (1871-1914). O mundo industrializado e urbano vivia um período de otimismo e desfrutava as novas tecnologias com grande satisfação. A eletricidade, o automóvel, o avião, o telefone, a fotografia, o animatógrafo, proporcionavam novos hábitos a um mundo capitalista. No entanto, ao clima da Belle Époque seguiu-se um período de grande perturbação, de mudanças profundas. Nas artes, as experiências revolucionárias desenvolvidas por Picasso, Matisse, Brancusi questionaram e rejeitaram as representações convencionais. Em busca de novas direções apareceram, movimentos e tendências como o cubismo, o surrealismo, o abstracionismo e o futurismo.

\begin{abstract}
A guerra de 1914-1918 veio influenciar profundamente o meio artístico e a vida quotidiana na sua generalidade. Perante os horrores que se viviam, os artistas e os escritores sentiram necessidade de denunciar os valores de uma sociedade que tornou a guerra possível e os avanços de uma ciência cujos progressos tinham contribuído para a destruição de uma parte da humanidade. Nos anos posteriores à guerra, surgiram, assim, outras correntes artísticas, que reflectiam o pessimismo e o horror que a guerra trouxera ao ser humano. (PROENÇA, 2015, p. 653)
\end{abstract}

A arquitetura libertou-se das formas revivalistas procurando responder, de uma forma racional, a novos hábitos de vida. O racionalismo, o funcionalismo, o organicismo, indicavam um novo caminho estético com recurso a novos materiais, como o betão armado e o aço. Na música Schonberg, Weber e as influências do Jazz com Stravinsky; e o Bailado com Diaghilev, propõem novos caminhos. Também a literatura foi revolucionada por Proust, Joyce, Breton, e Hemingway entre outros.

Em Portugal, a vitória dos republicanos em 5 de outubro de 1910, permitiu instituir um regime que favorecesse o aumento da liberdade, do progresso e da justiça social, ainda que os resultados obtidos não fossem os esperados. Para o fracasso dos 16 anos de regime (1910-1926) contribuíram a permanente instabilidade política, a participação de Portugal na I Guerra Mundial, as dificuldades internacionais, os graves problemas financeiros, económicos e sociais. Porém apesar das dificuldades, o clima mais liberalizante que caracterizou este período possibilitou a ocorrência de importantes modificações nos âmbitos da cultura, dos comportamentos e das mentalidades. 
Os governos republicanos desenvolveram uma obra bastante progressiva nos campos da legislação social e do ensino, mas a agitação política e social que caracterizou este período impediu que muitas das propostas dos republicanos fossem concretizadas. Uma das razões que contribuíram para que uma parte da sociedade portuguesa retirasse o seu apoio aos governos republicanos, especialmente nos meios rurais, foram as más relações que aqueles mantiveram com a Igreja Católica. A difícil situação económica e financeira herdada da Monarquia contribuiu também para impedir a concretização de muitas das promessas dos republicanos [...]. (PROENÇA, 2015, p.619)

\section{ENSINO EM PORTUGAL NA I REPÚBLICA}

Em Portugal os anos da I República foram marcados por uma grande instabilidade política e social e pela separação entre a igreja e o Estado. A característica marcante da forma republicana de entender o exercício do governo é a convicção de que para construir uma nova ordem, liberal e democrática deve proceder-se à instrução e esclarecimento dos povos, divulgando conhecimento e colocando-o ao serviço da transformação e construção sociais (PATRIARCA, 2012). Este movimento marcou as reformas educativas deste período, inspiradas em perspetivas pedagógicas modernas com o objetivo de desenvolver a instrução pública, oficial, obrigatória, gratuita e laica.

Uma das áreas a que os republicanos prestaram maior dedicação foi ao ensino. Na reforma de 1911 criaram dois ciclos: o ensino primário elementar obrigatório, com a duração de três anos; e o ensino primário complementar, com a duração de dois anos. Relativamente ao ensino secundário, só em 1918 se realizaram as primeiras transformações, nomeadamente no ensino técnico profissional, que passou a ser ministrado na Escola de Artes e Ofícios, nas Escolas Industriais, nas Escolas Preparatórias e no Instituto Superior Técnico, para o ensino industrial e Aulas Comerciais, nas Escolas Comerciais e Institutos Comerciais para o ensino comercial. O ensino superior foi aquele que sofreu grande alteração, uma vez que o monopólio da Universidade de Coimbra deixou de existir. O decreto de 22 de março de 1911 veio criar duas novas universidades, uma em Lisboa e outra no Porto. Para os republicanos a educação era o grande meio de desenvolvimento da sociedade:

Ainda durante o período monárquico, os republicanos criaram, por todo o país, inúmeros centros escolares, onde, além de ministrarem o ensino, realizavam conferências políticas. Por isso, após a vitória de 1910, a republica introduziu importantes mudanças no ensino, que se 
traduziram numa nova ideia de escola e em novas formas de pensar a educação e a formação para a cidadania. (PROENÇA, 2015, p. 657).

O governo da Primeira República encontrou Portugal numa realidade educativa muito distante dos restantes países da Europa. As taxas de analfabetismo rondavam os $75 \%$, sendo de $81 \%$ para as mulheres. De modo a combater rapidamente o analfabetismo recorreram a "escolas móveis", que chegaram a ser frequentadas por 200.000 estudantes. Para além das "escolas móveis" o Estado expandiu a rede escolar primária, não conseguindo, contudo alcançar todo o país, continuam a existir no interior do país muitas regiões sem escola.

Contudo para os republicanos, ensinar a ler e a escrever é apenas um ponto de partida de um percurso em que fica clara a distinção entre "instrução" - com vista à transmissão de técnicas escolares - e "educação", que procura formar mentalidades e criar vontades, na perspectiva de que o ser humano é moldável e que a idade adulta é determinada pela aprendizagem que se faz na infância (RAMOS, 1994, p. 414).

A primeira reforma republicana da instrução primária, a cargo de João de Barros e com a colaboração de João de Deus Ramos, estabelece a diferença entre o conceito de instrução para o de educação e a formação do caráter isenta da doutrina religiosa. Na Reforma do Ensino Infantil, Primário e Normal, consignada no Decreto da Reforma de 29 de Março de 1911.

O homem vale, sobretudo, pela educação que possui, porque só ela é capaz de desenvolver harmonicamente as suas faculdades, de maneira a elevarem-se-lhe ao máximo em proveito dele e dos outros [...] Portugal precisa de fazer cidadãos, essa matéria-prima de todas as pátrias, e, por mais alto que se afirme a sua consciência colectiva, Portugal só pode ser forte e altivo no dia em que, por todos os pontos do seu território, pulule uma colmeia humana, laboriosa e pacífica, no equilíbrio conjugado da força dos seus músculos, da seiva do seu cérebro e dos preceitos da sua moral. (MAGALHÃES, 2012, p. 6)

Para além das escolas (DOMINGUES, 2000), as bibliotecas tiveram um lugar privilegiado, uma vez que permitiam o acesso ao conhecimento. Razão pela qual os municípios do país foram convidados a criar bibliotecas municipais de acordo com as suas necessidades e recursos. Entre 1914 e 1915 são criadas Bibliotecas Móveis. O Estado destina uma verba de 2000 escudos para a criação de vinte bibliotecas, cada uma constituída por uma caixa-estante transportável que acomodaria os livros. 
Contudo, apesar das reformas educativas da República, os resultados não foram os esperados, ficando muito aquém das expectativas.

\begin{abstract}
A grande instância de republicanização dos espíritos em que tinham confiado, as escolas públicas, haviam falhado espetacularmente. Não houve maior decepção durante toda a República (v. Barros, Educação, p.21). Mais tarde alguns atribuíram mesmo a desgraça dos republicanos de 1910 ao fracasso da escolarização. Depois do impulso inicial, em 1911 (de 5550 escolas, em 1910, passou-se a 6400), o ritmo parou. Entre 1911 e 1926 criaram-se menos escolas do que aquelas que apareceram em 1911). Além disso uma parte estava fechada: em 1913, por exemplo, 800 (12\%) das escolas existentes não funcionavam. (RAMOS, 2001, p. 541).
\end{abstract}

Segundo Raquel Patriarca (2012), as medidas legislativas que procuraram fazer cumprir a obrigatoriedade escolar demonstraram dificuldade em mudar a mentalidade da população. Recorreram ao auxilio da igreja para incentivarem os pais a enviarem os filhos à escola, contudo a sociedade portuguesa maioritariamente pobre e marcadamente rural, dependia da mão de obra infantil.

Contudo, ainda que os projetos educativos e as reformas do ensino tivessem ficado muito aquém do esperado, com a implantação da República assiste-se a um aumento do interesse pela literatura para crianças. Interesse esse que já se tinha manifestado no final do século XIX, com a industrialização e a reforma dos ensinos primário e secundário levada a cabo por Passos Manuel, em 1836; a legislação sobre a leitura elementar e as reflexões sobre a educação de Antero de Quental e de Ramalho Ortigão, e ainda a criação em 1896 do Ministério da Instrução e das classes infantis que antecedem o ensino primário, com o objetivo de formar as famílias portuguesas que viviam num profundo estado de analfabetismo.

\title{
3 A ILUSTRAC̣ÃO PARA A INFÂNCIA EM PORTUGAL NO INÍCIO DO SÉCULO XX
}

No caso português, até ao início do século $X X$, era quase inexistente uma produção literária infantil. Esta resumia-se a adaptações e traduções de obras estrangeiras sem qualquer preocupação com os verdadeiros interesses do público-alvo.

\footnotetext{
A legislação derivada da constituição de 1911 apresenta projectos importantes para as crianças: bibliotecas escolares, definição dos objectivos da educação, ensino
} 
primário gratuito e obrigatório. Na referida Constituição de 1911, no nㄴ 4 do artigo 3 do título III, consigna-se a liberdade da criança; desenvolve-se o ensino infantil oficial que durará até 1936. O reconhecimento de que a criança passou a ser consumidor forte de leitura - mesmo que indirectamente constitui fenómeno da primeira metade do século XX. Daí à passagem da criança a grande consumidor autónomo de jornais (comics), livros e discos, vão poucos anos. É como consumidor - ou promotor insistente de consumo que a criança parece ganhar um certo estatuto de poder... (ROCHA, 1992, p. 53).

De acordo com Raquel Patriarca (2012), o intervalo temporal entre 1911 e 1926 regista a publicação de 246 livros para crianças e jovens, dos quais 191 são primeiras edições, que representam 77,6\% das obras publicadas ao longo deste período. A média anual durante os dezasseis anos da I República mais que duplica o valor aferido ao longo dos quarenta anos da Monarquia Constitucional, chegando a registar a publicação anual de 15,3 livros, valor que, se contarmos apenas as primeiras edições, reduz para 11,9 livros.

Em Portugal, durante as primeiras duas décadas do século $X X$, defendeu-se uma literatura para crianças de boa qualidade. Referência para as obras de Aquilino Ribeiro, António Sérgio e Carlos Selvagem, que a entendem mais como leitura de encantamento do que de aprendizagem, recheada de ilustrações que abandonam o seu estigma decorativo para se passarem a assumir num papel participante e interpretativo. (SILVA, S., 2011, p. 91).

Conforme refere Natércia Rocha (1992), com a queda da monarquia as mulheres constituíam a maioria do professorado, tentando combater os catastróficos $75 \%$ de analfabetos da população portuguesa. As professoras republicanas praticavam o Ensino Livre, liberto da influência religiosa, tanto nos Centros Escolares Republicanos, como nos colégios particulares e nas escolas oficiais. Entre as intelectuais republicanas destacavam-se algumas pioneiras dos direitos da mulher e da literatura para a infância, como Ana de Castro Osório e Maria O'Neill (Lisboa, 1873-Oceano Atlântico, 1932), poeta e jornalista, autora única de uma coleção de livros para crianças, a Biblioteca para a Infância, publicada entre 1913 e 1924,. A coleção, de dezassete volumes, publicada na editora livraria Lisboa, Parceria António Maria Pereira, contou com várias segundas e terceiras edições, que se estenderam até 1927. As capas e as ilustrações do miolo são da autoria de Joaquim Guilherme Santos Silva, com o pseudónimo Alonso (Lisboa, 1871- Sintra, 1948), um dos mais prolíficos ilustradores do seu tempo. Conforme refere Jorge Silva: 
Toda a gramática gráfica, da composição à tipografia, não se repete uma única vez ao longo das dezassete capascartaz evoluindo do sabor oitocentista ao modernismo geometrizante de Os Bonecos da Joaninha. As ilustrações do miolo, em sóbrio preto, no total de três centenas e meia, usam as convenções oitocentistas, como os primeiros planos a corpo inteiro das personagens, a modelação de volume e profundidade através do traço e as cercaduras geométricas em segundo plano que emolduram a ação. $\mathrm{O}$ preciosismo anatómico de Alonso, emparelha-o com outros dois seus contemporâneos, Alfredo Morais e Alberto de Sousa. Sem o dramatismo do primeiro e as meias tintas do segundo, Alonso e a sua linha clara deram a Maria O'Neill e à Biblioteca Para a Infância, uma elegância requintada, feita de belos vestidos e atavios, brinquedos e criadas, que ilustravam bem e disfarçavam mal os privilégios da caridosa elite republicana. (SILVA, 2015).

Figura 1 - Capas da coleção Biblioteca para a Infância (n.2, n.6 e n.15).
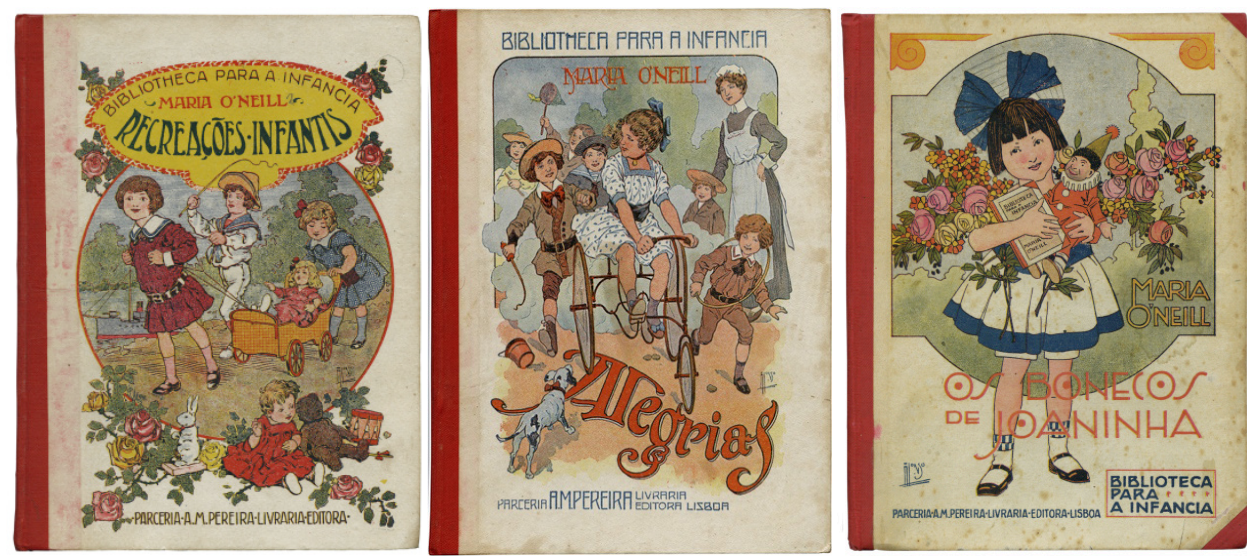

Fonte: Acervo pessoal de Jorge Silva. Título: Alonso. (SILVA, 2015).

Nomes como Milly Possoz (Lisboa, 1888-1968), uma artista plástica de origem belga e uma figura destacada da primeira geração de pintores modernistas portugueses. Regressada a Portugal em 1909, integra o movimento modernista emergente participando nas Exposições de Humoristas e Modernistas, sendo também das poucas artistas da sua geração a organizar exposições individuais do seu trabalho, consagrando-se como uma das mais importantes artistas portuguesas da primeira metade do século XX. Excelente desenhadora, colabora como ilustradora em numerosas publicações, como as revistas ABC, a Athena, a Contemporânea, A llustração Portuguesa, entre outras. Ilustra obras infantis e juvenis como O Jardim das Mestras (1914) de Manoel de Sousa Pinto. das edições Aillaud e Bertrand. Em 1922, de jane Bensaude, As Desgraças de uma Família Persa Colecção «Para as Crianças» da editora Lusitania. Ainda em 1922 ilustra Viagens Aventurosa de Felicio e Felizarda ao Polo Norte, da editora Lusitania. 
Raquel Roque Gameiro produziu uma vasta obra na literatura para a infância e na documentação de costumes tradicionais, onde se revelou exímia aguarelista, herança genética do pai Alfredo Roque Gameiro. O Livro de Bébé (1917; 3. a edição, 1925), um álbum ou diário, anotado pelos pais, editado pela Papelaria Guedes, registava diferentes fases dos primeiros anos de vida da criança. Se alguns dos registos são universais, como o primeiro dente ou a primeira palavra, outros poderiam pertencer apenas a uma elite, como a primeira vacina, a primeira papa ou o primeiro exame. Há quatro versões do livro, entre 1917 a 1969. Na primeira, as ilustrações Belle Époque pertencem a Raquel Roque Gameiro e os versos ao escritor Delfim Guimarães. Na 2ª edição de 1925, mantiveram-se as quadras, mas Raquel redesenhou os episódios no seu caraterístico traço a uma cor. Na terceira versão, com data provável para os anos 40, Raquel renovou as ilustrações para os mesmos temas mas os textos pertencem a vários autores, adicionando episódios finais relacionados com o aumento da escolaridade e a influência da Igreja.

A imutabilidade do traço nas segunda e terceira versões, que acumularam reedições sucessivas ao longo de três décadas, acrescenta um interesse adicional à sua comparação. Podemos apreciar dois retratos de época, onde evoluem trajes, penteados e hábitos sociais. Evolui também a gramática decorativa da ilustradora, da luxuriante natureza vegetal Art Nouveau de 1925 à sóbria Art Deco, de ornamentação mais geométrica. (SILVA, J., 2011a)

Mamia, nome artístico de Maria Emília Roque Gameiro (1901, Amadora-1996), filha de Alfredo Roque Gameiro, mestre da ilustração histórica e etnográfica em aguarela, irmã de Raquel Roque Gameiro, ilustradora de livros infantis e revistas de moda, autora de quadradinhos para as revistas Lusitas e Fagulha. Em traço linear, Mamia ilustrou vários livros para crianças como Varinha de condão, com textos de Fernanda de Castro e Tereza Leitão de Barros, de 1924; e em duas marcantes edições da Livraria Bertrand, Bonecos falantes (1925) e Papagaio Real (1926), ambos de Carlos Selvagem. Em 1929 Mamia ilustra Dias Felizes, com texto de Maria Paula de Azevedo, o n20 da coleção Biblioteca dos pequeninos, edição da tipografia da Empreza Nacional de Publicidade, sucessora da Empreza Diário de Notícias. Durante esta década e desta coleção, mas edição da empresa Diário de Notícias, com textos de Emília de Sousa Costa, Mamia ilustra outros números, do mesmo modo que Raquel Roque Gameiro, Alfredo Moraes, Vasco Lopes de Mendonça, Álvaro Duarte d'Almeida, ou Eduardo Malta. Os Contos do Joãosinho, também com textos de

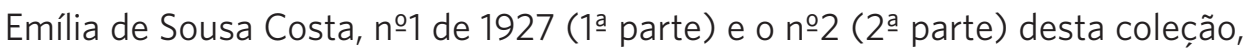
foram respetivamente ilustrados por Raquel e Mamia Roque Gameiro. 
Figura 2 - Capa e três páginas interiores da obra Dias Felizes de Maria Paula de Azevedo e ilustrações de Mamia Roque Gameiro. Edição Empreza Nacional de Publicidade (1929).
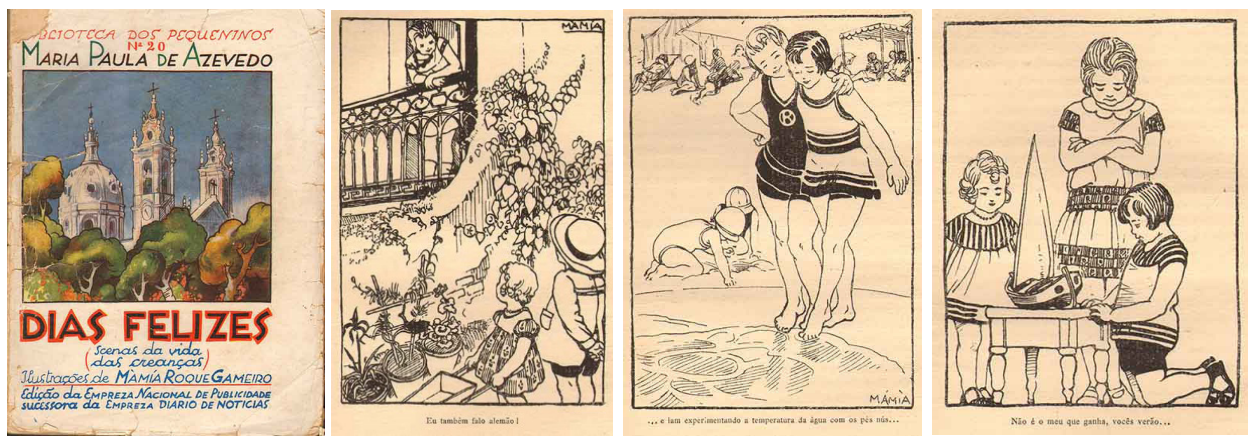

Fonte: Azevedo (1929).

Blog Tribo dos Pincéis. Informação Biblioteca Nacional de Portugal.

Na década de 20, Leal da Câmara ilustra uma série de obras de Ana de Castro Osório. Em 1921, A Princeza Muda, capa ilustrada com duas cores e interior com 17 ilustrações coloridas manualmente a uma cor. Em 1922, da Lusitânia Editora, Casa de Meu Pai, com capa e interior com 16 ilustrações a duas cores. Em 1924, também de Ana de Castro Osório, O Livrinho Encantador, Livro de Leitura para a 2ª Classe, da Lusitânia Editora, com capa e 34 ilustrações no interior com apenas uma cor.

\begin{abstract}
Os últimos anos da segunda década do século registaram já características bem marcadas no que refere a leituras para crianças. A comercialização ganha força e impõe critérios. A imprensa corre à conquista de um público que até então quase ignorara. Para além dos jornais expressamente dedicados às crianças, quase todos os grandes diários organizam suplementos infantis que têm logo grande aceitação [...]. [A década de 20] foi uma época excepcionalmente rica e movimentada que não teve continuação adequada nas décadas seguintes. (ROCHA, 1992, p. 63).
\end{abstract}

Obra de Fernanda de Castro, Mariazinha em África (10 edição, 1925), impresso pela Empresa Literária Fluminense, revela-nos a surpreendente evolução dos primeiros ilustradores modernistas portugueses. Sarah Afonso (1899-1983), pintora e futura mulher de Almada Negreiros, apresenta na primeira edição de 1925, um traço forte e uma representação figurativa sintética. O sucesso da obra fez acontecer em 1929 uma nova edição, em que Sarah Afonso revelou uma mudança para os cânones da segunda geração de modernista, através de uma representação a traço fino e descritivo.

"Sarah explorou o lado mágico e sensual da África negra, cuja arte tribal influenciou as vanguardas estéticas ocidentais e os ritmos endiabrados das jazz-bands dos night clubs lisboetas da década de vinte." (SILVA, 2012). 
De acordo com Susana Lopes Silva (2011) os livros deste período apresentam capas resistentes, cartonadas e forradas com tecido ou percalina e habitualmente são gravadas. Apresentam normalmente uma imagem central, rodeada por elementos ornamentais e quando a cor invade as ilustrações, fá-lo explorando fortes contrastes delineados por linhas negras afirmadas.

Figura 3 - Mariazinha em África, obra de Fernanda de Castro e ilustrações de Sarah Afonso. A ilustração da esquerda, com cor, pertence à capa e as restantes ao interior da obra. 1a edição Empresa Literária Fluminense (1925)
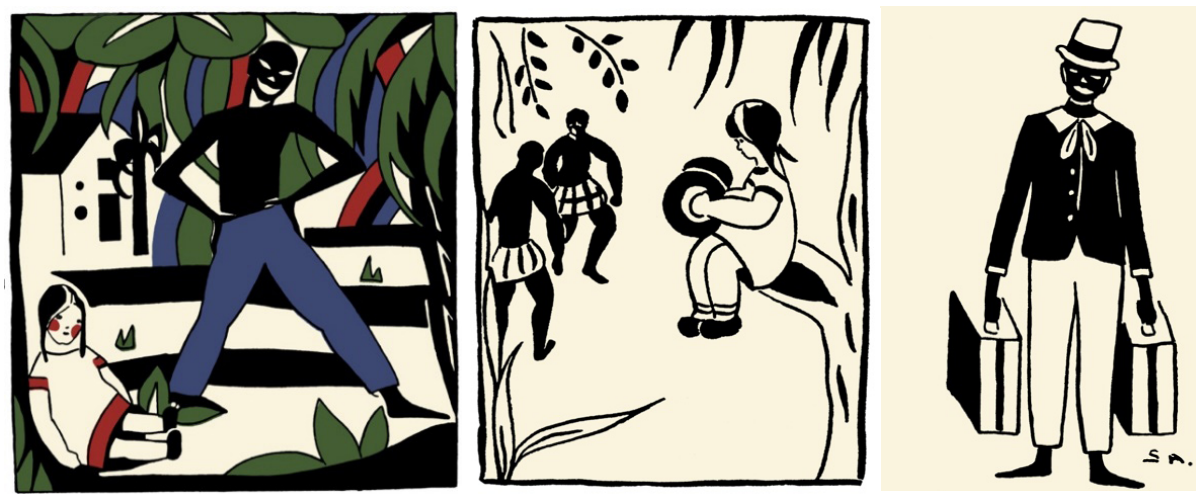

Fonte: Acervo pessoal de Jorge Silva. Título: Mariazinha Africanista. (SILVA, 2012).

Figura 4 - Mariazinha em África obra de Fernanda de Castro e ilustrações de Sarah Afonso. Empresa Literária Fluminense (1929)
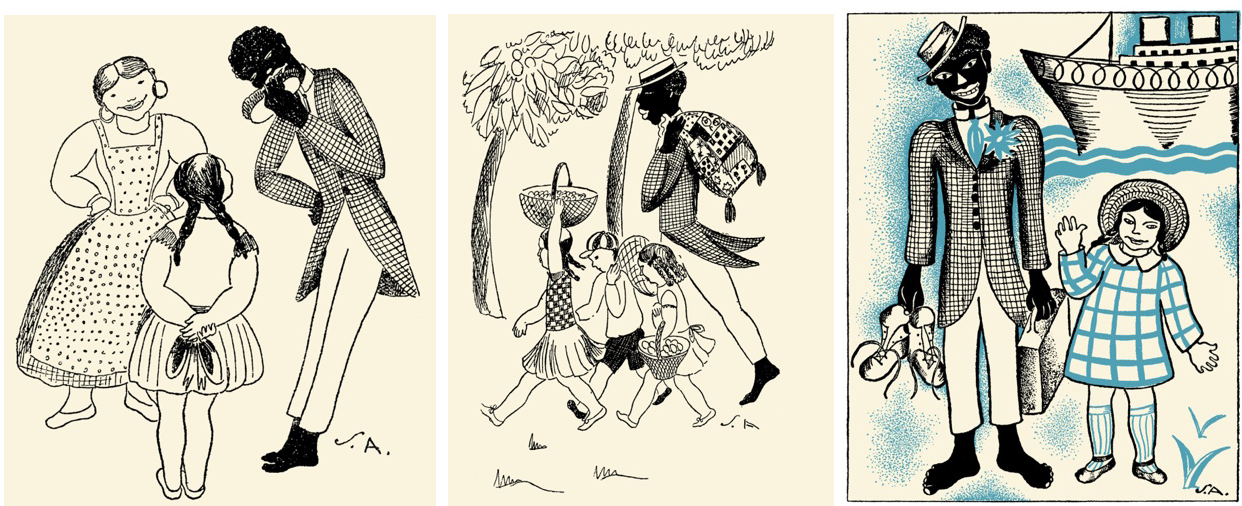

Fonte: Acervo pessoal de Jorge Silva. Título: Mariazinha Africanista. (SILVA, 2012).

A primeira revista, o «Gafanhoto», surge pela primeira vez em 1903, ainda nos prenúncios da República, e mantém-se até 1948. Mas é durante a década de 20, surgiu um grande número de publicação de jornais e suplementos, dedicados às crianças de que são exemplo ABCzinho (1921); O Bébé (1923); Notícias Miudinho (1924); Sportsinho (que contou com a colaboração de Stuart de Carvalhais); O Pintainho (1924 e conta com a colaboração de Rocha Vieira); Pim-Pam-Pum (1925), cuja direção estava a cargo de Augusto Santa-Rita e de Eduardo Malta); Novidades dos Pequeninos (1926); Semana Infantil (1927, cuja direção era da responsabilidade de Correia Marques); O Comércio Infantil (1928, com direção de Estefânia Cabreira e Oliveira Cabral e colaboração de Emília Sousa e Costa); O Bébé Ilustrado (1928, sob a direção de Cândido Torrezão e com ilustrações de Santos Silva, o Alonso), O Senhor Doutor; O Mosquito e O 
Papagaio. Esta última, uma revista católica, para miúdos, publicada pela empresa proprietária do magazine Renascença. Nasceu a 18 de Abril de 1935 e terminou no número 722, no ano de 1949 com a saída de Simões Müller. Fez parte de uma época em que as revistas infantis portuguesas entretiveram as crianças. Fundada e dirigida pelo famoso escritor infanto-juvenil Adolfo Simões Müller. Tom, iniciou-se na literatura infantil com o Tiroliro, suplemento infantil de $A$ Voz, também de inspiração católica. No Papagaio foi responsável pelo grafismo inicial, ilustrações e histórias aos quadradinhos.

"As suas capas para os primeiros números foram uma das faces mais criativas do Modernismo português, com os seus palhaços, crianças e papagaios em composições bidimensionais de cores primárias, fundos planos e cabeçalhos mutantes" (SILVA, J., 2011b).

Figura 5 - ABC-zinho suplemento para crianças da revista ABC. Capa da edição n. 6 de 16 de janeiro e n.7 de 6 de fevereiro de 1922, ilustradas por Cotinelli Telmo, diretor do jornal. À direita, Banda desenhada e texto de Stuart Carvalhais sob o pseudônimo de Albino, fazendo publicidade à marca de chocolates S.I.C.
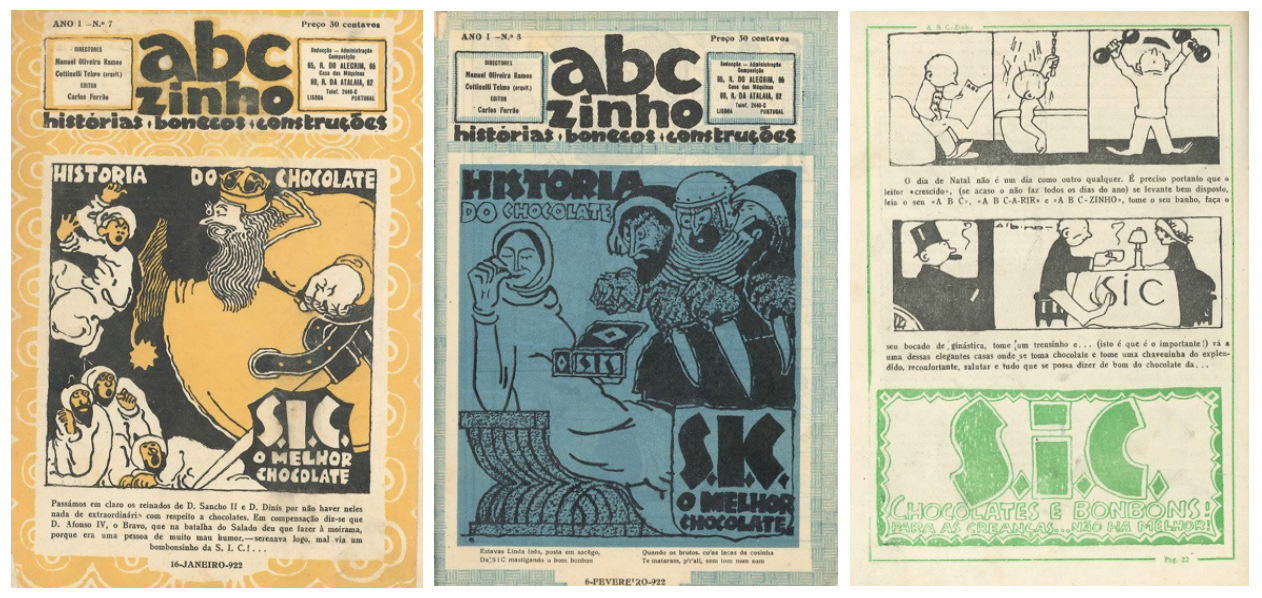

Fonte:Lino (2016).

Foram inúmeros os ilustradores que nasceram ou colaboraram na revista. José de Lemos, Ilberino dos Santos, Rudy, José Viana, Vasco Lopes de Mendonça, Arcindo Madeira, Méco, Júlio Resende e José Ruy. O Papagaio teve a honra de publicar pela primeira vez em 1936, fora dos países francófonos, as aventuras de Tintin. Até ao final dos anos 30 estes jornais mantêm as mesmas características, contendo secções de adivinhas, charadas, concursos, correio dos leitores, contos, poemas, canções e desenhos.

\section{CONSIDERAC̣ÕES FINAIS}

Podemos concluir que durante as duas primeiras décadas do século $X X$, a literatura para a infância em Portugal sofre influências da conjuntura sociocultural e política da época. Longe do esperado, o aumento da instrução gera o aumento da leitura, e a literatura passa a conquistar lentamente um espaço 
que até então não fora possível. Como consequência a ilustração para a infância desenvolve-se a partir deste período deixando um belíssimo legado de obras de autores portugueses, quer ao nível do texto, quer da ilustração. Pautado por um trabalho menos conservador e mais livre de academismos, que procurou aproximar-se ao que de mais moderno se passava na Europa. No entanto, na opinião de Natércia Rocha (1992), a vasta listagem, ainda que incompleta dos jornais para crianças e dos seus principais colaboradores, é revelador do interesse manifestado pelas publicações destinadas às crianças, durante este período, sem continuação nas décadas seguintes. 


\section{REFERÊNCIAS}

AZEVEDO, Maria Paula. Dias felizes. [S. I.: s. n.], 1929. Disponível em: http:// tribop.pt/TPd/17/17. Acesso em: 13 ago. 2018.

DOMINGUES, M.A. Mapa mínimo de relações: adaptação de um instrumento gráfico para a configuração da rede de suporte social do idoso. Dissertação de mestrado. São Paulo: Faculdade de Saúde Pública da USP. 2000.

LINO, Geraldes. Etiquetas: ABC-zinho, publicidade em BD, Stuart Carvalhais. In: LINO, Geraldes. DIVULGANDO BANDA DESENHADA. BD publicitária na revista $A B C$-zinho. Portalegre, PT, 17 out. 2016. Disponível em: http:// divulgandobd.blogspot.com/2016/10/bd-publicitaria-na-revista-abc-zinho. html. Acesso em: 13 ago. 2018.

MAGALHÃES, Justino. República e regimentação escolar: o estatuto fundante da I reforma republicana do ensino. In: ADÃO, Áurea; SILVA, Carlos Manique da; PINTASSILGO, Joaquim. (org.). O Homem vale, sobretudo, pela educação que possui: revisitando a primeira reforma republicana do ensino infantil, primário e normal. Lisboa: Instituto da Educação da Universidade de Lisboa, 2012.

PATRIARCA, Raquel. O livro infanto juvenil em Portugal entre 1870 e 1940: uma perspetiva histórica. 2012. Tese (Doutorado em Estudos da Criança) Universidade do Porto, Porto, 2012.

PROENÇA, Maria Cândida. Uma história concisa de Portugal. Lisboa: Temas e Debates, 2015.

RAMOS, Rui. História de Portugal. Lisboa: A esfera dos livros, 2001.

RAMOS, Rui. A segunda fundação: 1890-1926. In: MATTOSO, José (dir.). História de Portugal. Lisboa: Circulo de Leitores, 1994. v. 6.

ROCHA, Natércia. Breve história da literatura para crianças em Portugal. Lisboa: Biblioteca Breve, 1992.

SILVA, Jorge. Baby boom. Almanak Silva. 2011a. Disponível em: https:// almanaquesilva.wordpress.com/category/raquel-roque-gameiro/. Acesso em: 8 jun. 2018.

SILVA, Jorge. Mariazinha africanista. Almanak Silva. 2012. Disponível em: https://almanaquesilva.wordpress.com/category/sarah-afonso/. Acesso em: 8 jun. 2018.

Projética, Londrina, v.10, n.1 p. 105-118, jan./jun. 2019 
SILVA, Jorge. O papagaio do capitão Tom. Almanak Silva. 2011b. Disponível em: http://almanaquesilva.wordpress.com/2011/12/18/o-papagaio-docapitao-tom/. Acesso em: 8 jun. 2018.

SILVA, Jorge. Por bom caminho. Almanak Silva. 2015. Disponível em: https:// almanaquesilva.wordpress.com/category/alonso/. Acesso em: 3 jun. 2018.

SILVA, Susana L. A ilustração portuguesa para a Infância no século XX e movimentos artísticos: influências mútuas, convergências estéticas. 2011. Tese (Doutorado em Estudos da Criança) - Universidade do Minho, Braga, 2011.

Data de submissão: 2018-08-08

Data de aceite: 2018-10-22 